\title{
Preoperative exercise in patients undergoing total knee arthroplasty: a pilot randomized controlled trial
}

\author{
Pascale Gränicher ${ }^{1,2^{*}} \mathbb{D}$, Thomas Stöggl ${ }^{3}$, Sandro F. Fucentese ${ }^{4}$, Rolf Adelsberger ${ }^{5}$ and Jaap Swanenburg ${ }^{6}$
}

\begin{abstract}
Background: The purpose of this study was to assess the effect of preoperative physiotherapy (PT) on functional, subjective and socio-economic parameters after total knee arthroplasty (TKA).

Methods: 20 patients (mean \pm SD: age $67 \pm 7$ years) scheduled for TKA at Balgrist University Hospital between July 2016 and March 2017 were randomly assigned to a control (CG) or intervention (IG) group. 3 to 4 weeks prior to surgery the IG completed 5 to 9 sessions of PT containing proprioceptive neuromuscular facilitation (PNF) techniques, endurance training and individually indicated interventions. Measurements were executed at baseline, preoperative and 3 months after TKA. The primary outcome measure was the Stair Climbing Test (SCT), secondary outcome measures were the knee range of motion (ROM) and the level of physical activity using Lysholm Score (LS) and Tegner Activity Scale (TAS). The subjective and socio-economic parameters were the Patients' Global Impression of Change (PGIC) scale, inpatient rehabilitation time, preoperative pain levels and metabolic equivalent (MET), postoperative intake of analgesics and overall costs.
\end{abstract}

Results: No difference between IG and CG was found for SCT $(F(2 / 36)=0.016, p=0.984, \eta 2=0.004)$. An interaction between group and time was shown for TAS $(F(18 / 1)=13.890)$ with an increase in the IG $(p=0.002, \eta 2=0.536)$.

The sub-item "pain" within the LS presented a higher pain-level in CG $(F(18 / 1)=4.490, p=0.048, \eta 2=0.974)$, while IG showed a higher preoperative MET compared to CG $(p=0.035)$. There were no other significant changes. The CG produced $21.4 \%$ higher overall costs, took more analgesics and showed higher preoperative pain levels than the IG.

Conclusions: Findings show that preoperative therapy improved the level of physical activity before and after TKA and resulted in a clinically relevant gain in TAS.

Trial registration: ClinicalTrials.gov Identifier; NCT03160534. Registered 19 May 2017

Keywords: Prehabilitation, Knee osteoarthritis, Preoperative physical therapy

\footnotetext{
* Correspondence: pascale.graenicher@balgrist.ch

${ }^{1}$ The University Center for Prevention and Sports Medicine (UCePS), Balgrist University Hospital, Forchstrasse 319, 8008 Zurich, Switzerland

${ }^{2}$ Department of Epidemiology, CAPHRI School for Public Health and Primary

Care, Maastricht University, Peter Debyeplein 1, 6229 HA Maastricht, The Netherlands

Full list of author information is available at the end of the article
}

(c) The Author(s). 2020 Open Access This article is licensed under a Creative Commons Attribution 4.0 International License, which permits use, sharing, adaptation, distribution and reproduction in any medium or format, as long as you give appropriate credit to the original author(s) and the source, provide a link to the Creative Commons licence, and indicate if changes were made. The images or other third party material in this article are included in the article's Creative Commons licence, unless indicated otherwise in a credit line to the material. If material is not included in the article's Creative Commons licence and your intended use is not permitted by statutory regulation or exceeds the permitted use, you will need to obtain permission directly from the copyright holder. To view a copy of this licence, visit http://creativecommons.org/licenses/by/4.0/ The Creative Commons Public Domain Dedication waiver (http://creativecommons.org/publicdomain/zero/1.0/) applies to the data made available in this article, unless otherwise stated in a credit line to the data. 


\section{Highlights}

- Prehabilitation improves levels of physical activity before and after total knee arthroplasty

- Clinically relevant benefits on Tegner Activity Scale after prehabilitation

- Tendencies for shorter inpatient rehabilitation after preoperative exercise

\section{Background}

Total knee arthroplasty (TKA) is the elective surgical procedure after failing conservative management in patients suffering from advanced knee osteoarthrosis (KOA) [45]. Often, severe KOA is accompanied by constant pain, restricted joint flexibility, weakness of the quadriceps muscle and reduced knee functionality in sports and activities of daily living (ADLs) [24, 37]. Although pain levels and joint flexibility are to be improved after surgery, 20 to $30 \%$ are not satisfied with the result $[7,38]$. These patients do not achieve significant symptomatic enhancement or their impairments in ADLs become even worse [21]. In their review, Canovas and Dagneaux [7] highlighted the ability of walking down the stairs as an important factor contributing to patients' satisfaction after TKA. This goal may be compromised, because a great proportion does not achieve comparable strength to healthy persons 2 years after TKA [34].

During preoperative waiting time, not only joint flexibility and pain levels get worse, but joint-surrounding muscles further atrophy due to reduced facilitation and neuromuscular inhibition [14]. As a result, perceived participation in ADLs and the level of physical activity (PA) deteriorate [32].

Several systematic reviews and meta-analyses showed that physiotherapeutic prehabilitation may reduce postoperative limitations in ADLs and improve functional outcomes after TKA [15, 42, 44, 46]. Promising training interventions accompanied by patient education are endurance training to improve overall fitness $[1,11,32]$ and proprioceptive neuromuscular facilitation (PNF) techniques to increase joint ROM, improve neuromuscular performance $[17,39]$ and reduce pain levels $[9,31$, 35]. But the lack of specific information in previously tested prehabilitation protocols concerning exercises, dosage and intensity makes it difficult to draw a conclusion $[32,44]$. There is no consent, which dosage should be applied in preoperative exercise therapy. It is a tightrope walk to apply the ideal individual training intensity and not provoking an exacerbation of pain symptoms at the same time in patients awaiting TKA [15, 32, 44].

In a timeframe of 3 to 4 weeks, it is realistic to improve overall cardiovascular capacity and neuromuscular performance in joint surrounding muscles [3] as well as influence pain levels in order to enhance functional performance in ADLs [28].

Preoperative levels of PA in patients awaiting TKA correlate with postoperative outcomes, even years afterwards $[25,32]$. Therefore, the aim of this study is to improve functional ability of the knee by training neuromuscular performance of the quadriceps and hamstring muscles and enhancing joint flexibility as well as aerobic capacity. Besides the functional benefits, the prehabilitation protocol applied within this study intends to improve subjective and socio-economic parameters such as preoperative pain levels, postoperative intake of painkillers, the length of stay at an inpatient rehabilitation facility and overall costs.

\section{Methods}

\section{Participants}

Eligible patients older than 18 years receiving unilateral TKA were asked to participate in the study and recruited over a period of 9 months (July 2016-March 2017) at the Department of Orthopaedics of Balgrist University Hospital. Patients were excluded from participation if they suffered from muscle weakness due to secondary neurological diagnosis, high Body Mass Index (BMI > $33.0 \mathrm{~kg} / \mathrm{m}^{2}$ ), depression, patellar instability, patella alta (Caton Deschamps Index $>1.2$ ) or if they showed signs of inflammation such as swelling, warming, acute pain or redness apart from lack of function, or a planned osteotomy of tibial tuberosity. No payment or compensation was given to the study participants.

\section{Design}

This is a pilot randomized controlled trial with patients being randomly assigned to an intervention group (IG) or control group (CG). All procedures followed the Helsinki Declaration and all participants provided written informed consent. The ethics committee of the Canton of Zurich approved the study under BASEC 201600258. ClinicalTrials.gov Identifier; NCT03160534. All measurements and therapy sessions were conducted at the Balgrist University Hospital, Zurich, Switzerland.

\section{Intervention}

The aim of the preoperative training intervention was to increase the level of PA in ADLs (e.g. walking up and down the stairs) while correcting evasive movements, improve neuromuscular coordination of the joint surrounding muscles and prevent relieving postures during these activities. The maintenance of a higher preoperative level of PA due to better joint flexibility, improved intramuscular coordination of the thigh muscles and increased overall aerobic capacity was aspired [49]. The training consisted of 5 to 9 sessions of physiotherapy within 3 to 4 weeks before surgery, with the following 
content: 1) 10-45 min endurance training on a bicycle ergometer, pedal trainer, treadmill, or crosstrainer (patients' choice) with light to moderate exercise intensity (40-70\% of maximum heart rate) without pain provocation; 2) PNF techniques of quadriceps and hamstring muscles known as the contract-relax-antagonist-contract (CRAC) form and conducted with the assistance of a physiotherapist [17, 39]; 3) patient education: patients were comprehensively informed during therapy sessions regarding the topics of self-training at home, pain management and coping strategies, answering questions concerning pre- and postsurgical procedures and jointfriendly, physiological movement patterns; 4) individual interventions when indicated, e.g. strengthening exercises [22], sensori-motor training (e.g. integration of proprioceptive inputs on balance and gait) $[13,30,48]$ or electromyostimulation training [20]. The strengthening exercises were performed underloaded (coordination at $10-20 \%$ of 1-Repetition Maximum (1RM)) or at submaximal intensity (strength endurance at $30-50 \%$ of $1 \mathrm{RM}$ and hypertrophy at $50-80 \%$ of $1 \mathrm{RM}$ ) and targeted muscles of the lower extremities (e.g. quadriceps, hamstrings, calves, abductors). The sensori-motor training consisted of balance exercises on one leg (3-4 sets à 30-60s), sessions on how to walk with crouches and training of physiological movement patterns in ADLs. Whereas, the CG was asked to keep their activity level the same as before the baseline measurement and not to start a new type of therapy or training during the preoperative stage. The intensity during every intervention was set as high as manageable without pain provocation.

\section{Assessments}

Outcomes were assessed on three measurement events; at baseline three to 4 weeks before surgery, immediately before surgery and at follow-up 3 months post-surgery. Following the baseline assessment, all patients were instructed to keep a personal diary during the three to 4 weeks prior to surgery as well as during the 3 months post-surgery period.

\section{Primary outcome}

The Stair Climbing Test (SCT) measures the time used to ascend and descend a flight of eight $16 \mathrm{~cm}$ high steps with a depth of $30 \mathrm{~cm}$ [12]. Patients were asked to complete the test at usual walking speed, feeling safe and comfortable. Light use of the handrail or assistive devices were allowed but not encouraged if the patient felt unsafe. The handrail was to be used only for guidance and not for pulling. Completion of a trial was determined when both feet arrived on the final stair. The time to negotiate the stairs was measured by a stopwatch, as this method shows excellent test-retest intercorrelations (0.93) [36] in SCT. The minimal detectable change is set at $0.102 \mathrm{~s}$ [23]. A practice trial was completed and the mean of three subsequent trials was used for analysis. A 30-s break was held between the practice trial and each of the following trials.

\section{Secondary outcomes}

The range of motion (ROM) of the involved knee was assessed by a standard goniometer (clear plastic, $18 \mathrm{~cm}$ of length) in supine position, where the patient was asked to slide the heel towards the buttock as close as possible. The examination of knee ROM in patients with KOA has adequate reliability with an ICC coefficient of 0.96 for flexion and 0.81 for extension [10] and the minimal detectable change lies at $7.9^{\circ}$ for flexion and $3.8^{\circ}$ for extension [29]. The Lysholm Score (LS) was used for assessment of patients' perception of knee function and activity level in ADLs [4, 40]. Scores were categorized from "poor" (64) to "excellent" (95-100), with a score of 100 being considered as symptom-free [40]. The item "pain" was analyzed separately in order to retrieve information about the change of pain levels before and after surgery. The Tegner Activity Scale (TAS) was applied for assessment of work and sporting activities. The patients indicated the highest level of participation that best described their current level of activity. A score of 0 represents "sick leave or disability pension because of knee problems" where a score of 10 stands for "competitive sports such as football or alpine skiing (national or international level) [40]. The German versions of the LS (Lysholm-G) and the TAS (Tegner-G) were validated for patients after TKA [40]. They showed acceptable psychometric performances for the Lysholm-G and the Tegner-G scales as outcome measures for patients after TKA. The smallest detectable change for the TAS equals 1.4 points and 1 point for the LS [47].

To determine the perceived level of change after surgery, the Patient Global Impression of Change (PGIC) questionnaire was assessed at follow-up. The patients self-rated on the scale from 1 "very much improved" to 7 "very much worse" [18]. It has been shown that the PGIC is valuable in evaluating physiotherapeutic outcomes, as it requires little time and therefore may be ideal for the clinical setting [41]. Information concerning the postoperative risk of discharge to a rehabilitation facility and length of stay at an inpatient rehabilitation was extracted from the clinic's information system.

\section{Subjective and socio-economic outcomes}

In their personal diary, all patients answered standardized questions about their preoperative pain level (daily), documented their daily activities in order to calculate their individual metabolic equivalent (MET) and listed total costs (e.g. preoperative therapies, walking aids, medication) prior to surgery. 
After surgery, patients had to document the amount and costs of postoperative medication and post-acute care services (e.g. payment for home health agencies) as well as the amount of rehabilitative ambulant physiotherapy sessions, in their diary until the follow-up measurement. Data regarding the amount of preoperative therapy sessions and prescribed length of stay at an inpatient rehabilitation facility was retrieved from the clinics information system in order to calculate the complete treatment costs.

\section{Randomization and blinding}

Allocation to the IG or CG followed a computergenerated randomization list. The group assignments were concealed in envelopes. The assignments were revealed after baseline testing by a secretary who was independent of the study. The recruiting investigator was unaware of the next participant's allocation and therefore blinded at baseline measurement. The same physiotherapist conducted all measurements and 81 out of 85 preoperative interventions, substituted by one other physiotherapist in case of absence. Both therapists followed a previously instructed, standardized intervention protocol. Preoperative and follow-up measurements were not blinded, as the same physiotherapist who carried out the preoperative interventions, acted as investigator. All three measurements were supervised by an independent and blinded collaborator in order to ensure objectivity. Patients were not replaced after dropout or withdrawal.

\section{Data analysis}

All data were checked for normality using the Shapiro Wilk test. Two-way ANOVA with repeated measures (2 groups, 3 time points) was applied for comparison of SCT, knee ROM, LS and TAS between the two groups and the three time points. Additionally, effect size Etasquared $\left(\eta^{2}\right)$ was calculated $(<0.02=$ trivial; 0.02 to $0.13=$ small; 0.13 to $0.26=$ medium; $>0.26=$ large). For the PGIC, clinically significant improvement was defined as very much or much improved condition (score 1 or 2) [41]. To determine significant group differences between the lengths of stay at inpatient rehabilitation facilities, mean values of stationary weeks were compared between the two groups by independent t-test. Level of significance was set at $\alpha=0.05$ for all comparisons.

The additional subjective and socio-economic outcomes were extracted from the personal diaries. Independent sample t-tests were used to compare the groups by 1) preoperative pain levels, 2) preoperative MET, 3) postoperative pain medication and 4) total costs. All statistical procedures were performed with IBM SPSS 23 statistical software package (SPSS Inc., Chicago, Illinois, USA).

\section{Results}

\section{Participant flow}

The flow of patients through the study is shown in Fig. 1.

\section{Characteristics}

Patients' characteristics are displayed in Table 1. There were more males in the IG, but no significant differences were observed between the groups at baseline. All patients suffered from severe KOA (Kellgren and Lawrence Grade 4) where the conservative approach has been exploited and indication for TKA given by the orthopedist.

\section{Adherence to the intervention program}

Two patients were not able to complete the full set of nine sessions due to absence (vacation, work). Overall exercise compliance was $96.7 \%$ regarding completion of diaries but there were no dropouts as all patients finished the study and no adverse events were reported within the study. Table 2 shows individual interventions of the IG during preoperative period.

\section{Effects}

No effects between the IG and CG were demonstrated for primary outcomes in SCT $(\mathrm{F}=0.252, p=0.621$, $\left.\eta^{2}=0.014\right)$.

The secondary outcomes revealed no change between the IG and CG in knee ROM ( $\mathrm{F}=0.350, p=0.561, \eta^{2}=$ 0.087 ), and LS ( $\mathrm{F}=1.877, p=0.188, \eta^{2}=0.253$ ), whereas the separate analysis of the pain-level as a sub-item of the LS showed a significant difference between IG and CG $\left(\mathrm{F}=4.490, p=0.048, \eta^{2}=0.974\right)$.

The TAS displayed an increase over time and group difference as well as a large effect size $(\mathrm{F}=13.890, p=$ $\left.0.002, \eta^{2}=0.941\right)$. There were no group differences in the PGIC ( $p=0.307)$ and the length of stay at a rehabilitation facility $(p=0.486)$. Results are shown in Table 3.

\section{Subjective and socio-economic outcomes}

There were beneficial effects within the IG as the calculated MET displays. When excluding interventionrelated activities, the IG was significantly more active during the preoperative phase compared to the CG ( $p=$ 0.035). Results are shown in Table 4.

After the intervention period, pain levels measured from baseline to preoperative assessment improved in the IG by $30 \%$, while the CG showed an improvement of $6.5 \%$ on NRS $(p=0.189)$. The evaluation revealed that the intake of painkillers was $21 \%$ higher in the CG compared to IG after surgery. The IG had an average length of intake of 1.9 months, whereas the CG was on medication for 2.4 months $(p=0.150)$. 


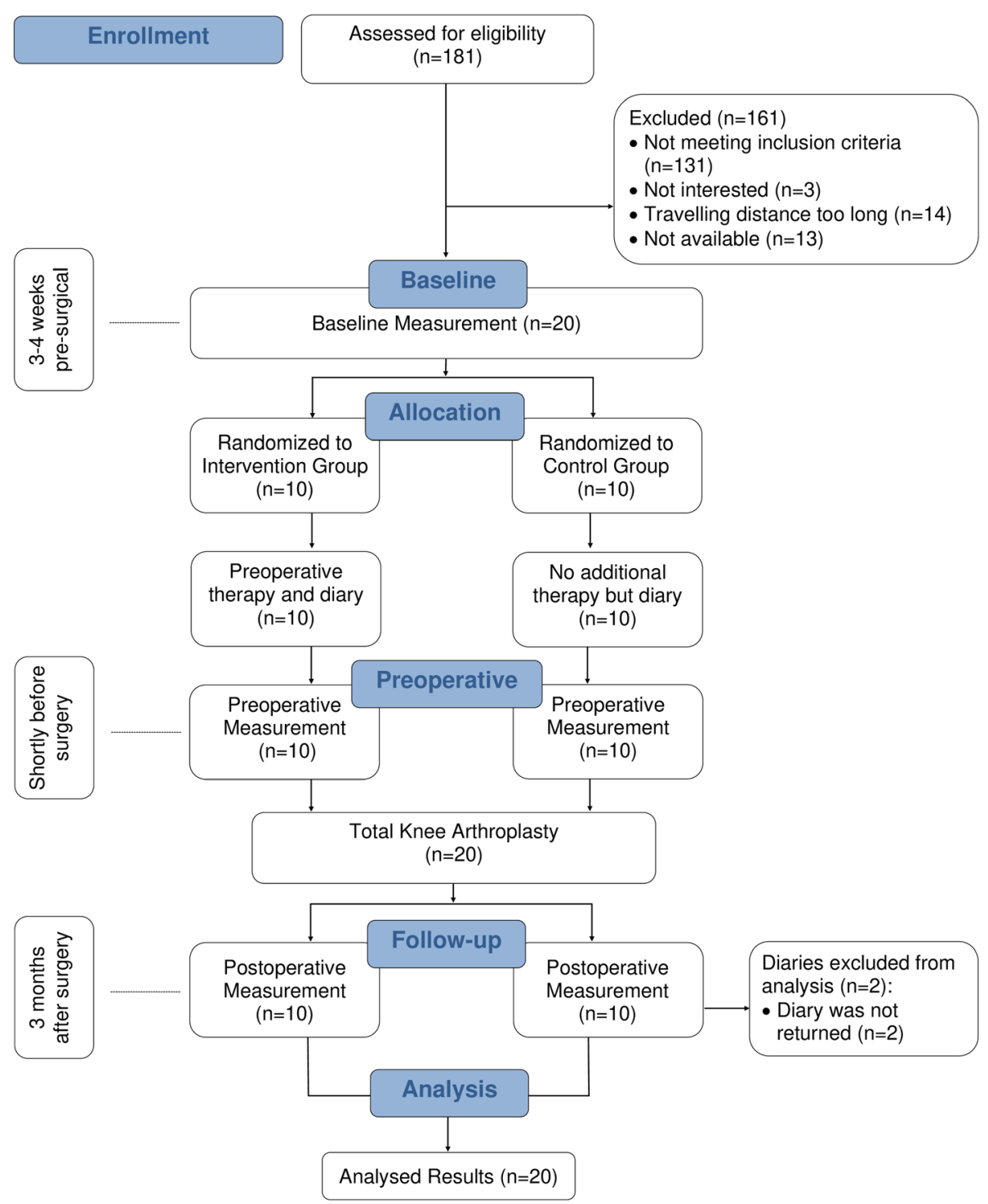

Fig. 1 The graph shows the flowchart of the TKA patients for the intervention study

Table 1 Baseline characteristics of all TKA patients and those in the intervention and control group

\begin{tabular}{|c|c|c|c|c|}
\hline & $\begin{array}{l}\text { Intervention Group } \\
(n=10)\end{array}$ & $\begin{array}{l}\text { Control Group } \\
(n=10)\end{array}$ & $\begin{array}{l}\text { All patients } \\
(n=20)\end{array}$ & $p$ \\
\hline & Mean (SD) Min-Max & Mean (SD) Min-Max & Mean (SD) Min-Max & \\
\hline Male & 7 & 5 & 12 & $\mathrm{n} / \mathrm{a}$ \\
\hline Female & 3 & 5 & 8 & $\mathrm{n} / \mathrm{a}$ \\
\hline Age (years) & $66.6(7.52) 53-80$ & $68.1(7.68) 55-81$ & $67.35(7.44) 53-81$ & 0.664 \\
\hline Height $(\mathrm{cm})$ & $174.2(11.17)$ 150-185 & 168.35 (6.59) 155-178 & 171.28 (9.42) 150.0-185.0 & 0.171 \\
\hline Weight (kg) & $90.2(19.378) 65-116$ & 80.3 (14.21) 56-103 & 85.25 (17.29) 56-116 & 0.209 \\
\hline Deviation of the knee joint axis $\left(^{\circ}\right)$ & $9.0(3.95) 3-14.5$ & $12.4(4.24) 6-19$ & $10.7(4.35) 3-19$ & 0.809 \\
\hline
\end{tabular}

Abbreviation: SD Standard deviation

$n=$ Sample size

$p=$ Independent $\mathrm{t}$-test

$\mathrm{n} / \mathrm{a}=$ not applicable

*significant $p<0.05$ 
Table 2 Individual interventions in IG and CG

\begin{tabular}{|c|c|c|c|}
\hline Patient-Nr. & Main problem / restriction (subj./obj.) & Prehabilitation & Total knee arthroplasty \\
\hline 01 & - Pain while walking or standing & - None. & $\begin{array}{l}\text { - Medacta GMK MyKnee, LBS } \\
\text { Sphere, Inlay } 10 \mathrm{~mm} \text { fixed } \\
\text { bearing medial pivot }\end{array}$ \\
\hline 02 & - Pain during knee loading & - None. & $\begin{array}{l}\text { - Zimmer Persona, Inlay } \\
10 \mathrm{~mm} \text { fixed bearing PS }\end{array}$ \\
\hline 03 & $\begin{array}{l}\text { - Reduced knee extension } \\
\text { - Pain }\end{array}$ & $\begin{array}{l}\text { - PNF stretching: hamstrings, quadriceps } \\
\text { - Endurance: cycling ergometer } \\
\text { - Patient education: pain management, } \\
\text { self-mobilization }\end{array}$ & $\begin{array}{l}\text { - Medacta GMK MyKnee, Inlay } \\
10 \text { mm fixed bearing PS }\end{array}$ \\
\hline 04 & - Pain during and after walking & - None. & $\begin{array}{l}\text { - Medacta GMK MyKnee, Inlay } \\
10 \text { mm fixed bearing PS }\end{array}$ \\
\hline 05 & $\begin{array}{l}\text { - Knee varus } \\
\text { - Non-physiological gait pattern } \\
\text { Reduced quadriceps innervation }\end{array}$ & $\begin{array}{l}\text { - PNF stretching: quadriceps } \\
\text { - Endurance: cycling ergometer } \\
\text { - Patient education: knee mechanics and } \\
\text { movement patterns } \\
\text { - Electromyostimulation training } \\
\text { training: quadriceps } \\
\text { - Sensori-motor training: gait training } \\
\text { without walking stick, balance exercises, } \\
\text { movement pattern }\end{array}$ & $\begin{array}{l}\text { - LINK Gemini SL, PorEx, Inlay } \\
10 \mathrm{~mm} \text { fixed bearing PS }\end{array}$ \\
\hline 06 & - Pain & $\begin{array}{l}\text { - PNF stretching: hamstrings, quadriceps } \\
\text { - Endurance: cycling ergometer } \\
\text { - Patient education: pain management, } \\
\text { self-training } \\
\text { - Sensori-motor training: balance, gait } \\
\text { - Strength training: coordination }\end{array}$ & $\begin{array}{l}\text { - Medacta GMK MyKnee Hinge, } \\
\text { Inlay } 10 \mathrm{~mm} \text { fixed bearing } \\
\text { Hinge }\end{array}$ \\
\hline 07 & $\begin{array}{l}\text { - Pain when walking up the stairs } \\
\text { or more than } 500 \mathrm{~m}\end{array}$ & - None. & $\begin{array}{l}\text { - Medacta GMK MyKnee, Inlay } \\
14 \text { mm fixed bearing PS }\end{array}$ \\
\hline 08 & - Pain when walking down the stairs. & - None. & $\begin{array}{l}\text { - Medacta GMK MyKnee, Inlay } \\
10 \text { mm fixed bearing PS }\end{array}$ \\
\hline 09 & $\begin{array}{l}\text { - Impaired gardening } \\
\text { - Pain after long walks }\end{array}$ & - None. & $\begin{array}{l}\text { - Medacta GMK MyKnee, Inlay } \\
14 \text { mm fixed bearing PS }\end{array}$ \\
\hline 10 & - Pain after resting for more than 15 min & - None. & $\begin{array}{l}\text { - Medacta GMK MyKnee } \\
\text { Revision, Inlay } 10 \mathrm{~mm} \text { fixed } \\
\text { bearing SC }\end{array}$ \\
\hline 11 & $\begin{array}{l}\text { - Pain } \\
\text { - Reduced performance at work }\end{array}$ & $\begin{array}{l}\text { - PNF stretching: hamstrings, quadriceps } \\
\text { - Endurance: walking on treadmill, cycling } \\
\text { ergometer } \\
\text { - Patient education: pain management, } \\
\text { self-training, movement patterns } \\
\text { - Electromyostimulation training: quadriceps } \\
\text { - Sensori-motor training: balance, gait } \\
\text { - Strength training: coordination, strength } \\
\text { endurance, hypertrophy }\end{array}$ & $\begin{array}{l}\text { - Zimmer Persona, Inlay } \\
10 \mathrm{~mm} \text { fixed bearing PS }\end{array}$ \\
\hline 12 & $\begin{array}{l}\text { - Reduced knee flexion } \\
\text { - Slight knee pain }\end{array}$ & $\begin{array}{l}\text { - PNF stretching: quadriceps } \\
\text { - Endurance training: cycling ergometer, } \\
\text { aqua jogging } \\
\text { - Patient education: pain management, } \\
\text { self-training /-mobilization } \\
\text { - Sensori-motor training: balance, gait }\end{array}$ & $\begin{array}{l}\text { - Medacta GMK MyKnee, Inlay } \\
12 \text { mm fixed bearing PS }\end{array}$ \\
\hline 13 & $\begin{array}{l}\text { - Reduced knee flexion and extension } \\
\text { - Pain } \\
\text { - Impaired sport performance }\end{array}$ & $\begin{array}{l}\text { - PNF stretching: quadriceps and hamstrings } \\
\text { - Endurance training: cycling ergometer } \\
\text { - Patient education: intensity strength } \\
\text { training, self-mobilization } \\
\text { - Sensori-motor training: gait, balance, } \\
\text { movement pattern } \\
\text { - Strength training: coordination, strength } \\
\text { endurance, hypertrophy }\end{array}$ & $\begin{array}{l}\text { - Zimmer Persona, Inlay } \\
10 \mathrm{~mm} \text { fixed bearing PS }\end{array}$ \\
\hline 14 & $\begin{array}{l}\text { - Knee valgus } \\
\text { - Slight pain } \\
\text { - Reduced ADL performance }\end{array}$ & $\begin{array}{l}\text { - PNF stretching: quadriceps, hamstrings } \\
\text { - Endurance training: crosstrainer } \\
\text { - Patient education: self-management, }\end{array}$ & $\begin{array}{l}\text { - Medacta GMK MyKnee } \\
\text { LBS Sphere, Inlay } 13 \mathrm{~mm} \\
\text { fixed bearing medial pivot }\end{array}$ \\
\hline
\end{tabular}


Table 2 Individual interventions in IG and CG (Continued)

\begin{tabular}{|c|c|c|c|}
\hline Patient-Nr. & Main problem / restriction (subj./obj.) & Prehabilitation & Total knee arthroplasty \\
\hline & & $\begin{array}{l}\text { physiological movement pattern } \\
\text { - Proprioceptive training: gait, balance, ADL } \\
\text { - Strength training: coordination, strength } \\
\text { endurance }\end{array}$ & \\
\hline 15 & $\begin{array}{l}\text { - Weakness } \\
\text { - Reduced knee flexion and extension } \\
\text { - Slight pain }\end{array}$ & $\begin{array}{l}\text { - PNF stretching: quadriceps, hamstrings } \\
\text { - Endurance training: pedal trainer } \\
\text { - Patient education: self-training, } \\
\text { self-mobilization } \\
\text { - Strength training: coordination, } \\
\text { strength endurance }\end{array}$ & $\begin{array}{l}\text { - Medacta GMK MyKnee, Inlay } \\
10 \mathrm{~mm} \text { fixed bearing PS }\end{array}$ \\
\hline 16 & $\begin{array}{l}\text { - Pain in the morning and after walking } \\
\text { down the stairs }\end{array}$ & - None. & $\begin{array}{l}\text { - Zimmer Persona, Inlay } \\
10 \mathrm{~mm} \text { fixed bearing PS }\end{array}$ \\
\hline 17 & $\begin{array}{l}\text { - Stiffness } \\
\text { - Pain after walking }\end{array}$ & - None. & $\begin{array}{l}\text { - Medacta GMK MyKnee LBS } \\
\text { Sphere, Inlay } 13 \mathrm{~mm} \text { fixed } \\
\text { bearing medial pivot }\end{array}$ \\
\hline 18 & - Pain when knee is loaded. & • None. & $\begin{array}{l}\text { - Zimmer Persona, Inlay } \\
11 \mathrm{~mm} \text { fixed bearing PS }\end{array}$ \\
\hline 19 & $\begin{array}{l}\text { - Knee varus, reduced knee flexion, } \\
\text { impaired sport performance }\end{array}$ & $\begin{array}{l}\text { - PNF stretching: quadriceps, hamstrings } \\
\text { - Endurance training: cycling ergometer } \\
\text { - Patient education: self-training /- } \\
\text { mobilization, movement patterns, } \\
\text { training intensity } \\
\text { - Sensori-motor training: gait, balance } \\
\text { - Strength training: coordination, strength } \\
\text { endurance, hypertrophy }\end{array}$ & $\begin{array}{l}\text { - Medacta GMK MyKnee LBS } \\
\text { Sphere, Inlay } 10 \mathrm{~mm} \text { fixed } \\
\text { bearing medial pivot }\end{array}$ \\
\hline 20 & $\begin{array}{l}\text { - Impaired 18-hole golf performance } \\
\text { due to pain }\end{array}$ & $\begin{array}{l}\text { - PNF stretching: quadriceps, hamstrings } \\
\text { - Endurance training: cycling ergometer, } \\
\text { treadmill walking } \\
\text { - Patient education: self-training/ } \\
\text { - mobilization, movement patterns, } \\
\text { training intensity } \\
\text { - Sensori-motor training: gait, balance } \\
\text { - Strength training: coordination, strength } \\
\text { endurance }\end{array}$ & $\begin{array}{l}\text { - Medacta GMK MyKnee } \\
\text { Revision, Inlay } 10 \text { mm fixed } \\
\text { bearing semiconstrained }\end{array}$ \\
\hline
\end{tabular}

Intensity strength training: coordination $=10-20 \%$ of 1 RM underloaded and not performed to momentary muscle failure; strength endurance $=30-50 \%$ of 1 RM performed to momentary muscle failure; hypertrophy $=50-80 \%$ of 1 RM performed to momentary muscle failure

Comparing the costs and amount of prehabilitation and rehabilitation; preoperative therapy sessions, postoperative stationary rehabilitation and therapies were calculated for each group. As Table 5 shows, the total costs of pre- and postoperative therapy and stationary rehabilitation were $21.3 \%$ higher in the CG (CHF 6704) compared to the IG (CHF 5273) $(p=0.730)[19,33]$.

\section{Discussion}

Changes during the intervention phase were not due to different preliminary settings, as homogeneity at baseline for both groups was demonstrated (see Table 3). A tendency in SCT indicated that the IG could maintain its level of mobility and functional performance, while the CG rapidly degraded towards the time of operation. This observation matches the findings of McKay et al. [28] and Fortin et al. [16]: Conditions of patients suffering from KOA become worse the closer surgery gets and prolonged waiting time has a negative effect on physical performance [14]. As Baker and McKeon [2] point out, patients with severe KOA also show negative alterations in climbing up and down the stairs before TKA.

By training and preserving physiological movement pattern and therefore functional performance of the knee using PNF techniques, postoperative transmission back to normal ADL activities seemed to be easier. Whereas the ability to climb stairs showed tendencies of improvement in the IG, knee ROM experienced a similar retrogression in both groups 3 months after surgery compared to the baseline assessment. As no maximum knee $\mathrm{ROM}$ is required to climb the stairs, a decreasing knee flexion did not necessarily influence the preoperative SCT.

In terms of perceived functional performance and participation in ADLs after TKA, the results in LS and TAS suggest faster recovery regarding knee stiffness, joint mobility and pain in the IG and indicate a significant influence of prehabilitaton on postoperative TAS outcome measures. The significant difference of preoperative MET may be an explanation, as the patients in IG were more active before, and therefore also after surgery [25]. 
Table 3 Results of primary and secondary outcomes on each assessed time point in both groups, changes ( $n=10$ in each group)

\begin{tabular}{|c|c|c|c|c|c|c|c|}
\hline \multirow[t]{3}{*}{ Measure } & \multicolumn{2}{|l|}{ Baseline } & \multirow[t]{2}{*}{ t-test } & \multicolumn{2}{|l|}{ Preoperative } & \multicolumn{2}{|l|}{ Postoperative } \\
\hline & $\overline{\mathrm{IG}}$ & $C G$ & & $\overline{\mathrm{IG}}$ & CG & $\overline{\mathrm{IG}}$ & CG \\
\hline & $\begin{array}{l}\text { Mean (SD) } \\
\text { Min-Max }\end{array}$ & $\begin{array}{l}\text { Mean (SD) } \\
\text { Min-Max }\end{array}$ & $p$ & $\begin{array}{l}\text { Mean (SD) } \\
\text { Min-Max }\end{array}$ & $\begin{array}{l}\text { Mean (SD) } \\
\text { Min-Max }\end{array}$ & $\begin{array}{l}\text { Mean (SD) } \\
\text { Min-Max }\end{array}$ & $\begin{array}{l}\text { Mean (SD) } \\
\text { Min-Max }\end{array}$ \\
\hline Stair Climbing Test (sec) & $\begin{array}{l}12.37(3.74) \\
6.58-18.26\end{array}$ & $\begin{array}{l}13.54(7.35) \\
6.14-27.33\end{array}$ & 0.658 & $\begin{array}{l}12.68(5.00) \\
5.60-23.58\end{array}$ & $\begin{array}{l}14.11(9.19) \\
5.71-34.87\end{array}$ & $\begin{array}{l}12.58(4.64) \\
6.70-23.23\end{array}$ & $\begin{array}{l}13.59(5.30) \\
5.13-24.02\end{array}$ \\
\hline $\mathrm{ROM}\left({ }^{\circ}\right)$ & $\begin{array}{l}113.30(16.99) \\
90-135\end{array}$ & $\begin{array}{l}120.60(15.43) \\
80-135\end{array}$ & 0.328 & $\begin{array}{l}116.70(13.24) \\
95-135\end{array}$ & 116.20 (17.39) 70-134 & $\begin{array}{l}100.50(18.65) \\
60-120\end{array}$ & $\begin{array}{l}103.5(13.69) \\
90-128\end{array}$ \\
\hline Lysholm Score (all items) & $\begin{array}{l}53.50(21.59) \\
26-90\end{array}$ & $\begin{array}{l}59.00(13.59) \\
41-84\end{array}$ & 0.504 & $\begin{array}{l}70.70(20.21) \\
30-97\end{array}$ & $\begin{array}{l}54.80(18.52) \\
13-83\end{array}$ & $\begin{array}{l}87.10(9.04) \\
72-100\end{array}$ & $\begin{array}{l}69.11(14.87) \\
52-96\end{array}$ \\
\hline Lysholm Score (only pain) & $\begin{array}{l}10.50(7.25) \\
0-20\end{array}$ & $\begin{array}{l}9.50(4.38) \\
5-15\end{array}$ & 0.713 & $\begin{array}{l}13.00(10.06) \\
0-25\end{array}$ & $\begin{array}{l}9.00(6.15) \\
0-20\end{array}$ & $\begin{array}{l}25.00(0.00) \\
25-25\end{array}$ & $\begin{array}{l}16.50(9.14) \\
5-25\end{array}$ \\
\hline Tegner Activity Scale & $\begin{array}{l}2.50(0.71) \\
1-3\end{array}$ & $\begin{array}{l}2.10(0.738) \\
1-3\end{array}$ & 0.232 & $\begin{array}{l}3.10(0.568) \\
2-4\end{array}$ & $\begin{array}{l}2.00(0.816) \\
1-3\end{array}$ & $\begin{array}{l}3.80(0.789) \\
3-5\end{array}$ & $\begin{array}{l}2.50(0.850) \\
1-4\end{array}$ \\
\hline PGIC & & & 0.307 & & & $\begin{array}{l}2.50(2.17) \\
1-7\end{array}$ & $\begin{array}{l}2.10(1.45) \\
1-4\end{array}$ \\
\hline $\begin{array}{l}\text { Length of stay in } \\
\text { rehabilitation facility (weeks) }\end{array}$ & & & 0.486 & & & $\begin{array}{l}1.0(1.49) \\
0-4\end{array}$ & $\begin{array}{l}1.5(1.64) \\
0-4\end{array}$ \\
\hline
\end{tabular}

Abbreviations: IG Intervention Group, CG Control Group, ROM Range of motion, PGIC Patients Global Impression of Change, SD Standard deviation

Values given as Mean (SD) or range $=$ Min-Max

$p=$ Independent $\mathrm{t}$-test

${ }^{*}$ significant $p<0.05$

Similar results showed the study by Clode et al. [11]: After an eight-week exercise and education program, patients' pain and level of PA in ADL improved prior to TKA. The patients felt well prepared and therefore, postsurgical satisfaction was positively influenced by the program. The minimal clinically relevant change for the TAS equals 1.4 points [47], which is nearly exceeded by comparing the ratings at follow-up measurements in both groups in the present study but is below the value after considering changes from baseline to follow-up assessment. The IG improved almost up to level 4, which indicates an active lifestyle [28] and implies a significant enhancement in quality of life [43]. Due to the small sample size, single outliers strain distinct results and make it difficult to draw conclusive statements from these questionnaires. Nevertheless, it may be important to consider the IG's development of a more active lifestyle as high ratings in TAS prior to surgery [43] and preoperative MET suggested when drawing conclusions to perceived outcome after surgery. Whether the reason for these results is a better intramuscular coordination due to PNF techniques, individual exercises or improved aerobic capacity is not fully clear.

The findings of the meta-analysis by Chen et al. [8] who observed a significantly reduced rate of inpatient rehabilitation after preoperative physiotherapy match the difference in length of stay between IG and CG presented in this study. It has to be taken into account that in Switzerland, the decision for or against inpatient rehabilitation does not exclusively depend on the medical condition after surgery but, among other things; e.g. on the insurance policy. After the four-week prehabilitation phase, the case costs added by postoperative inpatient rehabilitation were $33 \%$ higher in the CG compared to the IG, mainly due to inpatient care. An extended prehabilitation period may shorten the length of stay at the

Table 4 Summary of socio-economic outcomes in both groups measured at different time intervals

\begin{tabular}{lllll}
\hline Measure & IG & CG & $p$ & Ratio IG: CG \\
& Mean / Min-Max & Mean / Min-Max & \\
\hline Preoperative pain level (NRS) & $4.27 / 0-8$ & $4.53 / 0-8$ & 0.524 & $1: 1.06$ \\
Change of pain level (NRS) from baseline to preoperative assessment & $1.5 / 0-8$ & $0.38 / 0-4$ & 0.189 & $4: 1$ \\
Preoperative MET & $982.4 / 0-3033$ & $438.2 / 0-4181$ & $0.035^{*}$ & $1.7: 1$ \\
Postoperative medication (number of months) & $1.9 / 1-3$ & $2.4 / 1-3$ & 0.150 & $0.79: 1$ \\
Pre- and rehabilitation costs per patient (CHF) & 5272.8 & 6704.4 & 0.730 & $0.79: 1$ \\
\hline
\end{tabular}

Abbreviations: IG Intervention Group, CG Control Group, NRS Numeric Rating Scale, MET Metabolic Equivalent, SD Standard deviation

Values given as Mean (SD) or range $=$ Min-Max

$p=$ Independent t-test

*significant $p<0.05$ 
Table 5 Summary of average total costs of pre- and postoperative therapies per patient

\begin{tabular}{lll}
\hline Costs per patient & IG (CHF) & CG (CHF) \\
\hline Preoperative PT & 467 & 0 \\
Postoperative PT & 1161 & 1223 \\
In-patient rehabilitation & 3645 & 5481 \\
Total costs per patient (CHF) & 5273 & 6704 \\
\hline
\end{tabular}

Abbreviations: PT Physical therapy, IG Intervention Group, CG Control Group

hospital and therefore reduce overall case costs even more, as Calatyud et al. [6] managed with an eight-week, high-intensity training and Rooks et al. [37] achieved by applying a six-week intervention program prior to TKA.

The advantageous results of preoperative pain levels documented in the patients diaries and revealed by the item "pain" in the LS in IG compared with CG can be explained by the findings of Lewit and Simons [26]: Their outcome showed an immediate pain relief as well as a long-lasting pain reduction after PNF techniques. The current results support these findings as not only the IG's pain levels within the LS improved between baseline and preoperative assessment, but the effect was transferred to the 3 months follow-up where this group reported no pain at all. Baker and McKeon [2] as well as Canovas and Dagneaux [7] emphasize this statement by pointing out the importance of preoperative pain as a relevant prognostic factor in postoperative outcome and quality of life after TKA. A similar correlation was found for preoperative level of PA and postoperative outcome.

A higher preoperative MET predicts a better functional result, as Scott et al. [38] showed in their work. A possible connection may be drawn to the shorter time in inpatient rehabilitation facilities documented by the IG in this study, as its patients were significantly more active before surgery compared to the CG. There is a tendency for a higher presurgical level of PA and a lower pain score to predict faster recovery, including reduced pain medication, as findings of Baker and McKeon [2] confirm.

Individual estimation of societal participation defined by the scores in TAS provided valuable evidence supporting preoperative physiotherapy. Prehabilitation improves pre- and postoperative level of PA in ADLs. This may affect perceptions directly by giving the patients more insight and control over their medical care and therefore reporting higher physical functioning at follow-up measurement [5]. As lower fear-avoidance beliefs correlate with lower pain levels and better performance [27], patient education prior to TKA adds up to functional benefits. Further, the diverse expectations and demands of patients receiving a TKA show that today's health system is facing multi-layered challenges. Decreasing financial resources, and at the same time, increasing claims for health services in function- and participation-related areas are making the situation more acute [32]. The clinical focus has moved away from implant survival to patient-reported outcomes. The focus of scientific evaluation begins to concentrate on a patient's experience and level of satisfaction after TKA and not only on objective outcome parameters $[1,21]$.

\section{Interference factors and limitations}

The study we present here was a pilot study and the number of participants therefore low. Nevertheless, patient compliance was high, with $96.7 \%$ compared with other studies reporting 75-90\% [46].

The strong point of this study was its randomized controlled design. But, although randomization process and baseline assessment were blinded, the same physiotherapist performed all three measurements as well as the preoperative intervention program. In that context, the prehabilitation program was also conducted in one single clinic and the same surgical team undertook all operations. As postoperative care was individual and took place in various private practices and clinics, there was no possibility to verify the reported data on the amount of therapy sessions. Therefore, the calculation for the total amount of costs depended partly on subjective reports of the patients.

\section{Conclusion}

The results of this pilot randomized controlled trial indicate that presurgical physiotherapy likely has a small effect on SCT, knee ROM, LS and the length of stay at a rehabilitation facility. The IG increased its level of PA by almost 2 points on the TAS after TKA, where recreational sport is possible again. The effect in the IG was strong when compared with the CG, suggesting evidence that preoperative intervention enhances the level of PA in ADL prior and after TKA.

The significant improvements after prehabilitation presented in TAS and the sub-item "pain" within the LS as well as in preoperative MET emphasize the trend for accelerated recovery and improved patients' perceived outcome by optimizing prognostic parameters prior to TKA.

\section{Abbrevations \\ 1RM: 1-Repetition maximum; ADLs: Activities of daily living; BMI: Body Mass Index; CG: Control group; CRAC: Contract-relax antagonist-contract; IG: Intervention group; KOA: Knee osteoarthritis; LS: Lysholm Score; MET: Metabolic equivalent; $\eta^{2}$ : Eta-squared; PA: Physical activity; PGIC: Patients' Global Impression of Change; PNF: Proprioceptive neuromuscular facilitation; PT: Physiotherapy; ROM: Range of motion; SCT: Stair Climbing Test; TAS: Tegner Activity Scale; TKA: Total knee arthroplasty}

\section{Acknowledgements}

I would like to thank all my co-authors for contributing to my master thesis and finally, to this article. I am especially grateful to Dr. Jaap Swanenburg, who always had an open ear for my questions and never got tired in answering them. Further, I very much appreciate the support of Richard Stoke, who corrected all the small and not so small mistakes I made while writing this article in a foreign language. 


\section{Authors' contributions}

PG: Guarantor, writing the paper, designing the study, monitoring progress, undertaking recruitment, data collection and interventions and deciding on the analytic strategy. TS: Monitoring progress, revising the writing and deciding on the analytic strategy. SF: Supporting recruitment, revising the writing. RA: Supporting data collection, revising writing. JS: Initiating the study, designing it, monitoring progress, deciding on the analytic strategy and supporting and revising the writing. All authors read and approve the final manuscript.

\section{Funding}

None.

\section{Availability of data and materials}

The datasets used and/or analyzed during the current study are available from the corresponding author on reasonable request.

\section{Ethics approval and consent to participate}

All procedures followed the Helsinki Declaration and all participants provided written informed consent. The ethics committee of the Canton of Zurich approved the study under BASEC 2016-00258. ClinicalTrials.gov Identifier; NCT03160534.

\section{Consent for publication}

Not applicable.

\section{Competing interests}

The authors declare that they have no competing interests.

\section{Author details}

${ }^{1}$ The University Center for Prevention and Sports Medicine (UCePS), Balgrist University Hospital, Forchstrasse 319, 8008 Zurich, Switzerland. ${ }^{2}$ Department of Epidemiology, CAPHRI School for Public Health and Primary Care, Maastricht University, Peter Debyeplein 1, 6229 HA Maastricht, The Netherlands. ${ }^{3}$ Department of Sport and Exercise Science, University of Salzburg, Schlossallee 49, 5400 Hallein/Rif, Austria. ${ }^{4}$ Department of Orthopaedic Surgery, Balgrist University Hospital, University of Zurich, Forchstrasse 340, 8008 Zurich, Switzerland. ${ }^{5}$ Wearable Computing Lab Zurich, ETH Zurich, Gloriastrasse 35, 8092 Zurich, Switzerland. ${ }^{6}$ Integrative Spinal Research ISR, Department of Chiropractic Medicine, Balgrist University Hospital, Forchstrasse 340, 8008 Zurich, Switzerland.

\section{Received: 31 March 2020 Accepted: 15 July 2020}

\section{Published online: 05 August 2020}

\section{References}

1. Arden N, Altman D, Beard D, Carr A, Clarke N, Collins G, et al. Lower limb arthroplasty; can we produce a tool to predict outcome and failure, and is it cost-effective? An epidemiological study. Programme Grants Appl Res. 2017; 5(12):29-79.

2. Baker CS, McKeon JM. Does preoperative rehabilitation improve patientbased outcomes in persons who have undergone total knee arthroplasty? A systematic review. PM R. 2012;4(10):756-67.

3. Bant H, Haas HJ, Ophey M, Steverding M. Sportphysiotherapie. 1st ed. Stuttgart: Georg Thieme Verlag KG; 2011. p. 199-201.

4. Briggs KK, Steadmen JR, Hay CJ, Hines SL. Lysholm score and Tegner activity level in individuals with normal knees. Am J Sports Med. 2009;37(5):898901.

5. Brown K, Topp R, Brosky JA, Lajoie AS. Prehabilitation and quality of life three months after total knee arthroplasty: a pilot study. PMS. 2012;115(3): 765-74.

6. Calatayud J, Casaña J, Ezzatvar Y, Jakobsen MD, Sundstrup E, Andersen LL. High-intensity preoperative training improves physical and functional recovery in the early post-operative periods after total knee arthroplasty: a randomized controlled trial. Knee Surg Sports Traumatol Arthrosc. 2017; 25(9):2864-72.

7. Canovas F, Dagneaux L. Quality of life after total knee arthroplasty. Orthop Traumatol Surg Res. 2018;104(1S):41-6.

8. Chen H, Li S, Ruan T, Liu L, Fang L. Is it necessary to perform prehabilitation exercise for patients undergoing total knee arthroplasty: meta-analysis of randomized controlled trials? Phys Sportsmed. 2018;46(1):36-43.
9. Chow TP, Ng GY. Active, passive and proprioceptive neuromuscular facilitation stretching are comparable in improving the knee flexion range in people with total knee replacement: a randomized controlled trial. Clin Rehabil. 2010;24(10):911-8.

10. Cibere J, Bellamy N, Thome A, Esdaile JM, McGorm KJ, Chalmers A, et al. Reliability of the knee examination in osteoarthritis: effect of standardization. Arthritis Rheum. 2004;50(2):458-68.

11. Clode NJ, Perry MA, Wulff L. Does physiotherapy prehabilitation improve pre-surgical outcomes and influence patient expectations prior to knee and hip joint arthroplasty? Int J Orthop Trauma Nurs. 2018;30:14-9.

12. Dobson F, Hinman RS, Roos EM, Abbott JH, Stratford P, Davis AM, et al. OARSI recommended performance-based tests to assess physical function in people diagnosed with hip or knee osteoarthritis. Osteoarthr Cartil. 2013; 21(8):1042-52.

13. Doma K, Grant A, Morris J. The effect of balance training on balance performance and functional outcome measures following total knee arthroplasty: a systematic review and meta-analysis. Sports Med. 2018;48: 2367-85.

14. Felson DT, Lawrence RC, Hochberg MC, McAlindon T, Dieppe PA, Minor MA et al. Osteoarthritis: new insights. Part 2: treatment approaches. Ann Intern Med. 2000;133(9):726-37.

15. Ferrara PE, Rabini A, Maggi L. Effect of pre-operative physiotherapy in patients with end-stage osteoarthritis undergoing hip arthroplasty. Clin Rehabil. 2008;22:977-86.

16. Fortin PR, Clarke AE, Joseph L, Liang MH, Tanzer M, Ferland D, et al. Outcomes of total hip and knee replacement: preoperative functional status predicts outcomes at six months after surgery. Arthritis Rheum. 1999;42(8): 1722-8.

17. Gabriel DA, Kamen G, Frost G. Neural adaptations to resistive exercise. Sports Med. 2006;36(2):133-49.

18. Geisser ME, Clauw DJ, Strand V, Gendreau RM, Palmer R, Williams DA. Contributions of change in clinical status parameters to patient global impression of change (PGIC) scores among persons with fibromyalgia treated with milnacipran. Pain. 2000;149(2):373-8.

19. Gesundheitsdirektion Zürich. Rechtssetzung und Politische Rechte. Krankenversicherung (Referenztarife ab 2016) [Internet]. Amtsblatt des Kanton Zürich: Zurich (CH); 2016. https://gd.zh.ch/internet/ gesundheitsdirektion/de/themen/berufe/aerzte/ausserkantonalehospitalisation/_jcr_content/contentPar/downloadlist/downloaditems/2 07_1495456674192.spooler.download.1452590218808.pdf/verfuegung_ referenztarife_2016_amtsblatt.pdf. Accessed 24 Feb 2020.

20. Gondin J, Guette M, Ballay Y, Martin A. Electromyostimulation training effects on neural drive and muscle architecture. Med Sci Sports Exerc. 2004; 37(8):1291-9.

21. Hadlandsmyth K, Zimmermann MB, Wajid R, Sluka KA, Herr K, Clark CR, et al. Longitudinal postoperative course of pain and dysfunction following total knee arthroplasty. Clin J Pain. 2018;34(4):332-8.

22. Husby VS, Foss OA, Husby OS, Winther SB. Randomized controlled trial of maximal strength training vs. standard rehabilitation following total knee arthroplasty. Eur J Phys Rehabil Med. 2018;54:371-9.

23. lijima H, Shimoura K, Eguchi R, Aoyama T, Takahashi M. Concurrent validity and measurement error of stair climb test in people with pre-radiographic to mild knee osteoarthritis. Gait Posture. 2019;68:335-9.

24. Kwok IH, Paton B, Haddad FS. Does pre-operative physiotherapy improve outcomes in primary total knee arthroplasty? - a systematic review. J Arthroplast. 2015;30(9):1657-63.

25. Laverina C, D'Appuzzo M, Rossi MD, Lee D. Is postoperative function after hip or knee arthroplasty influenced by preoperative functional levels? J Arthroplast. 2009;24(7):1033-43.

26. Lewit K, Simons DG. Myofascial pain: relief by post-isometric relaxation. Arch Phys Med Rehabil. 1984;65(8):452-6.

27. Lowry V, Ouellet P, Vendittoli P, Carlesso LC, Widemann TH, Desmeules F. Determinants of pain, disability, health-related quality of life and physical performance in patients with knee osteoarthritis awaiting total joint arthroplasty. Disabil Rehabil. 2018;40(23):2734-44.

28. McKay C, Prapavessis H. Prehabilitation for TKA: preop and postop benefits. LER. 2012;4(10):65-9.

29. Mehta SP, Barker K, Bowman B, Galloway H, Oliashirazi N, Oliashirazi A. Reliability, concurrent validity, and minimal detectable change for iPhone goniometer app in assessing knee range of motion. J Knee Surg. 2017;30: 577-84. 
30. Moutzouri M, Gleeson N, Billis E, Panoutsopoulou I, Gliatis J. Physiotherapy. 2016;102(2):136-44.

31. Page P. Current concepts in muscle stretching for exercise and rehabilitation. Int J of Sports Phys Ther. 2012;7(1):109-19.

32. Peer MA, Rush R, Gallacher PD, Gleeson N. Pre-surgery exercise and postoperative physical function of people undergoing knee replacement surgery: a systematic review and meta-analysis of randomized controlled trials. J Rehabil Med. 2017:49(4):304-15.

33. Physioswiss. Tarifstruktur für physiotherapeutische Leistungen gültig ab 1 . Oktober 2016 [Internet]. Sursee (CH): Physioswiss; 2016. https://www. physioswiss.ch/media/1801/download/Tarifstruktur_okt_16.pdf?v=1. Accessed 24 Feb 2020.

34. Pozzi F, Snyder-Mackler L, Zeni J. Physical exercise after knee arthroplasty: a systematic review of controlled trials. Eur J Rehabil Med. 2013;49(6):877-92.

35. Reid DA, McNair PJ. Passive force, angle, and stiffness changes after stretching of hamstring muscles. Med Sci Sports Exerc. 2004;36(11):1944-8.

36. Rejeski WJ, Ettinger WH, Shumaker S, James P, Burns R, Elam JT. Assessing performance-related disability in patients with knee osteoarthritis. Osteoarthr Cartil. 1995;3:157-67.

37. Rooks DS, Huang JIE, Bierbaum BE, Bolus SA, Rubano J, Connolly CE, et al. Effect of preoperative exercise on measures of functional status in men and women undergoing total hip and knee arthroplasty. Arthritis Rheum. 2006; 55(5):700-8

38. Scott CE, Howie CR, MacDonald D, Biant LC. Predicting dissatisfaction following total knee replacement: a prospective study of 1217 patients. J Bone Joint Surg (Br). 2010;92(9):1253-8.

39. Sharman MJ, Cresswell AG, Riek S. Proprioceptive neuromuscular facilitation stretching: mechanisms and clinical implications. Sports Med. 2006;36(11): 920-39.

40. Swanenburg J, Koch PP, Meier N, Wirth B. Function and activity in patients with knee arthroplasty: validity and reliability of a German version of the Lysholm score and the Tegner activity scale. Swiss Med Wkly. 2014;144: w13976.

41. Swanenburg J, Gruber C, Brunner F, Wirth B. Patients' and therapists' perception of change following physiotherapy in an orthopedic hospital outpatient clinic. Physiother Theory Pract. 2015;31 (4):293-8.

42. Swank AM, Kachelman JB, Bibeau W, Quesada PM, Nyland J. Malkani, et al. Prehabilitation before total knee arthroplasty increases strength and function in older adults with severe osteoarthritis. J Strength Cond Res. 2011;25(5):318-25.

43. Tegner $Y$, Lysholm J. Rating systems in the evaluation of knee ligament injuries. Clin Orthop Relat Res. 1985;198:43-9.

44. Topp R, Swank AM, Quesada PM, Nyland J, Malaki A. The effect of prehabilitation exercise on strength and functioning after total knee arthroplasty. AAPM\&R. 2009;1 (8):729-35.

45. Varacallo M, Luo TD, Johanson NA. Total knee arthroplasty (TKA) techniques [Updated 2020 Mar 15] [Internet]. Treasure Island (FL): StatPearls Publishing; 2020 Jan-. https://www.ncbi.nlm.nih.gov/books/NBK499896/. Accessed 24 Feb 2020

46. Wang L, Lee M, Zhang Z, Moodie J, Cheng D, Martin J. Does preoperative rehabilitation for patients planning to undergo joint replacement surgery improve outcomes? A systematic review and meta-analysis of randomised controlled trials. BMJ Open. 2006;6(2):e009857.

47. Wirth B, Meier N, Koch PP, Swanenburg J. Entwicklung und Evaluation einer deutschen Version der Tegner Aktivitätsskala zur Erfassung der Funktion nach einer Verletzung des vorderen Kreuzbandes. Sportverletz Sportschaden. 2013;27(1):21-7.

48. Wodowski A, Swigler CW, Hongchao L, Nord KM, Toy PC, Mihalko WM. Proprioception and knee arthroplasty. A literature review. Orthop Clin N Am. 2016;47:301-9.

49. Zopf EM, Bloch W, Machtens S, Zumbé J, Rübben H, Marschner S, Kleinhorst C, et al. Effects of a 15-month supervised exercise program on physical and psychological outcomes in prostate cancer patients following prostatectomy: the ProRehab study. Integ Cancer Ther. 2015;14(5):409-18.

\section{Publisher's Note}

Springer Nature remains neutral with regard to jurisdictional claims in published maps and institutional affiliations.

Ready to submit your research? Choose BMC and benefit from:

- fast, convenient online submission

- thorough peer review by experienced researchers in your field

- rapid publication on acceptance

- support for research data, including large and complex data types

- gold Open Access which fosters wider collaboration and increased citations

- maximum visibility for your research: over $100 \mathrm{M}$ website views per year

At BMC, research is always in progress.

Learn more biomedcentral.com/submissions 